\title{
Neuroimaging and ophthalmologic findings in incomplete Susac syndrome
}

\author{
Neuroimagem e achados oftalmológicos na síndrome de Susac incompleta \\ Renata Cristina MÜLLER', Kenzo HOKAZONO², Bernardo Corrêa de Almeida TEIXEIRA', Rosana Hermínia SCOLA
}

A 19-year-old woman presented with sudden headache, dysarthria, paresthesia in upper limbs, memory and visual impairment.

Magnetic resonance imaging (MRI) revealed several round lesions in the supra- and infratentorial structures with hyperintensity in fluid-attenuated inversion recovery (FLAIR) and contrast enhancement, predominantly affecting the basal ganglia and central portions of the corpus callosum (Figure 1).
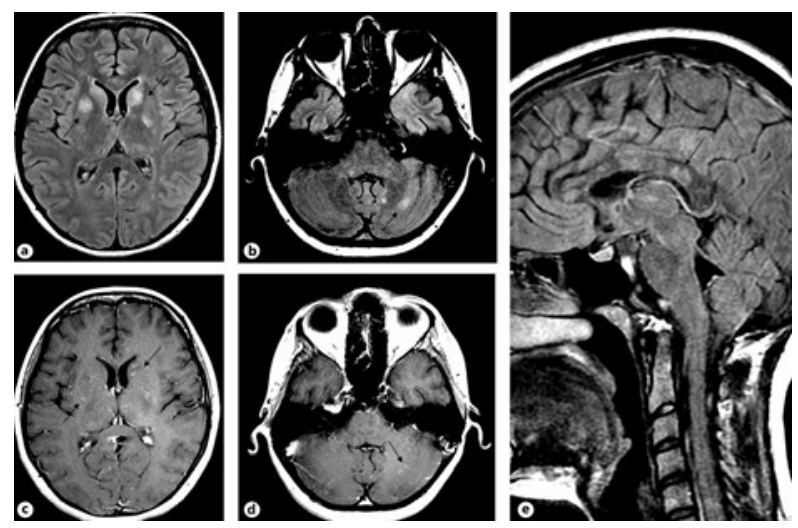

Figure 1. Brain magnetic resonance image (MRI) showing multiple bilateral round lesions with hyperintensity in fluid-attenuated inversion recovery (FLAIR) $(\mathrm{a}, \mathrm{c})$ and punctate contrast enhancement affecting the basal ganglia and the cerebellum on axial views (b, d) and typical "snowball" lesions in the central fibers of the corpus callosum on sagittal view (e). Lesions showed no abnormality on diffusion-weighted images (not shown)
Fluorescein angiography revealed multiple retinal branch artery occlusions in both eyes (Figure 2). Audiometry, somatosensory and visual evoked potentials were normal.

Susac syndrome is a rare autoimmune endotheliopathy characterized by a clinical triad of encephalopathy, visual disturbance and hearing loss, but complete clinical presentation is unusual ${ }^{1,2}$. Incomplete Susac syndrome is defined when only two criteria are present ${ }^{2}$.
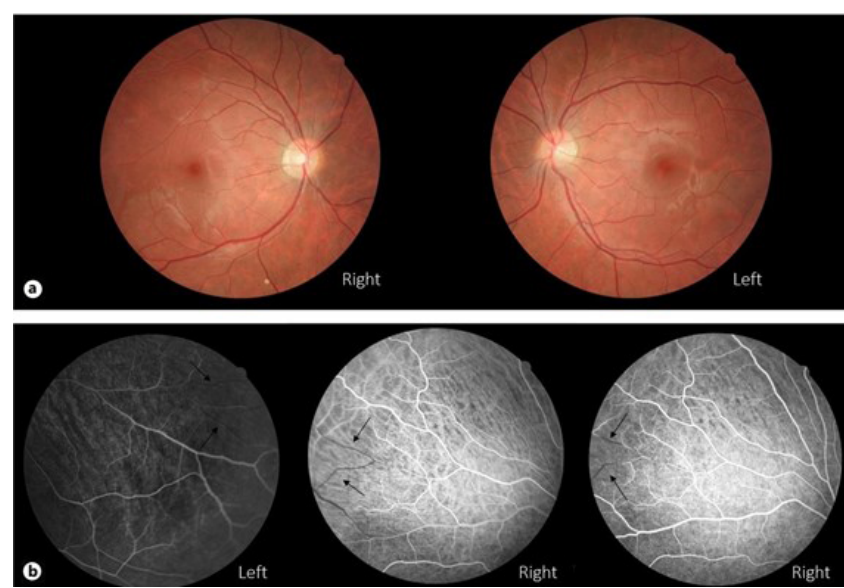

Figure 2. Fundus photograph showing normal optic disk, macula and retinal vascularization in both eyes (a). Fluorescein angiography demonstrating arterial occlusion in retinal equator of both eyes (b).
1. Monteiro ML, Swanson RA, Coppeto JR, Cuneo RA, DeArmond SJ, Prusiner SB. A microangiopathic syndrome of encephalopathy, hearing loss, and retinal arteriolar occlusions. Neurology. 1985 Aug;35(8):1113-21. https://doi.org/10.1212/wnl.35.8.1113
2. Vishnevskia-Dai V, Chapman J, Sheinfeld R, Sharon T, Huna-Baron R, Manor RS, Shoenfeld Y, et al. Susac syndrome: clinical characteristics, clinical classification, and long-term prognosis. Medicine (Baltimore). 2016 Oct;95(43):e5223. https://doi.org/10.1097/md.0000000000005223

1Universidade Federal do Paraná, Hospital de Clínicas, Unidade de Radiologia, Curitiba PR, Brazil.

2Universidade Federal do Paraná, Hospital de Clínicas, Unidade de Oftalmologia, Curitiba PR, Brazil.

${ }^{3}$ Universidade Federal do Paraná, Hospital de Clínicas, Unidade de Neurologia, Curitiba PR, Brazil.

Renata Cristina MÜLLER (iD https://orcid.org/0000-0002-6602-2101; Kenzo HOKAZONO (D) https://orcid.org/0000-0003-2897-6833;

Bernardo Corrêa de Almeida TEIXEIRA (D) https://orcid.org/0000-0003-4769-6562; Rosana Hermínia SCOLA (ID https://orcid.org/0000-0002-3957-5317

Correspondence: Renata Cristina Müller; E-mail: renatacmuller@gmail.com

Conflict of interest: There is no conflict of interest to declare.

Author's Contribution: The authors declare that they have each made important contributions to the acquisition, analysis, and interpretation of the data. All authors have critically revised the manuscript and have given their approval for the final version to be published.

Received on June 7, 2020; Received in its final form on June 15, 2020; Accepted on June 22, 2020. 